\title{
O papel do design da informação na curadoria digital do Museu da Pessoa
}

\author{
The role of information design on digital curation at the Museum of the Person
}

\begin{abstract}
Karen Kahn
Mestranda em Ciência da Informação pela Universidade Estadual Paulista "Júlio de Mesquita Filho" - UNESP, campus de Marília.

E-mail: karenkipnis@yahoo.com.br

Maria José Vicentini Jorente

Doutora em Ciência da Informação pela Universidade Estadual Paulista "Júlio de Mesquita Filho" - UNESP, campus de Marília. Professora do Departamento de Ciência da Informação e do Programa de Pós-Graduação em Ciência da Informação da Faculdade de Filosofia e Ciências - UNESP, campus de Marília.

E-mail: mjjorente@yahoo.com.br
\end{abstract}

\section{Resumo}

Contemporaneamente, Arquivos, Bibliotecas e Museus deixam de ser apenas ambientes físicos para adotar uma conformação também digital, tornando-se híbridos. O Museu da Pessoa, cujo fato museal são histórias de vida, possui característica própria, devido ao design estrutural de sua plataforma permitir tanto as ações institucionais top-down quanto colaborativas, bottom-up. O objetivo geral deste artigo é estudar as transformações tecnológicas do Museu da Pessoa a partir de sua criação em 1991. O objetivo especifico é entender como tais transformações, a partir do advento da Internet, inserem-se no paradigma pós-custodial ou paradigma de acesso; e o papel do Design da Informação na Curadoria Digital da plataforma que dá suporte ao Museu. A metodologia utilizada delineia-se como participativa indireta por meio de estudo histórico, observação planejada em sites, dissertações, teses, artigos científicos, documentos e livros, e descritiva. O trabalho se justifica pela necessidade de se conhecer novas formatações para a Curadoria Digital em instituições museológicas no âmbito da Ciência da Informação. Como resultado, espera-se a compreensão de possível modelo para a preservação e interação com histórias de vida e memórias, entendidas aqui como Patrimônio Memorial da Humanidade.

Palavras-chave: Informação e Tecnologia. Web 2.0. Curadoria Digital. Design da Informação. Museu da Pessoa.

\begin{abstract}
Contemporaneously, Archives, Libraries and Museums are not merely physical environments to also adopt a digital conformation, becoming hybrids. The Museum of the Person, whose museum fact are actually stories of life, has its own characteristics, due to the structural design of its platform to allow both institutional action topdown as collaborative, bottom-up. The aim of this article is to study the technological transformation of the Museum of the Person from its genesis in 1991. The specific objective is to understand how such transformations, from the advent of the Internet, are part of the post-custodial paradigm or paradigm access; and the role of Information Design in the Digital Curation platform that supports the museum. The methodology outlines itself as indirect participatory through historical study, observation planned on websites, dissertations, theses, scientific articles, papers and books, and descriptive. The work is justified by the need to meet new formats for Digital Curation in museological institutions within the Information Science. As a result, we expect understanding possible model for the preservation and interaction with life stories and memories, seen here as a World Heritage Memorial.
\end{abstract}

Keywords: Information and Technology. Web 2.0. Digital Curatorship. Information Design. Museum of the Person.

InCID: R. Ci. Inf. e Doc., Ribeirão Preto, v. 7, n. 2, p. 23-39, set. 2016/fev. 2017.

DOI: 10.11606/issn.2178-2075.v7i2p23-39 


\section{Introdução}

Inúmeras têm sido as discussões conceituais sobre a hibridização e convergência de linguagens, epistemologia e vocação genética das informações e da comunicação publicizada no âmbito dos ambientes digitais destinados à seleção, à salvaguarda, à organização, à classificação e à catalogação de documentos, obras e objetos colecionáveis. Na contemporaneidade, diversos fatores contribuíram para a criação de novos ambientes para o acesso e conversação entre os acervos e os sujeitos que buscam informação e conhecimento.

A natureza destes ambientes tem características que combinam sede física com a virtualidade, criando natureza hibrida ou que, ainda, podem ocorrer somente na virtualidade, sendo atualizados por meio de interfaces computacionais. Nestes ambientes pós-custodiais (RIBEIRO, 2010) ou de custódia ampliada, em que o fluxo informacional é potencializado pelas Tecnologias de Informação e Comunicação (TIC), tanto a equipe multidisciplinar de profissionais da informação institucional, anteriormente atrás do balcão, quanto o internauta (profissional ou não) devem se capacitar para adquirirem competências especificas do universo digital.

Neste contexto, observa-se que, assim como as bibliotecas e os arquivos, os museus se repensaram. Hoje o museu busca ser, ao mesmo tempo, tanto um ambiente convidativo, propício a diálogos e trocas de informações entre a instituição e os seus visitantes por meio de visitas orientadas, cursos, oficinas, palestras e workshops presenciais, assim como busca promover a interação entre seu acervo e diferentes públicos também em ambiência digital por meio de recursos de Design da Informação (DI) previstos em sua Curadoria Digital. Por meio de mediações culturais e institucionais atuam na Web 2.0 ou Web Social (SÁEZ VACAS, 2007), como um catalizador de vivências e experiências, previamente elaboradas por, entre outros, designers em equipe multidisciplinar. Recursos de DI, preveem convergências de linguagens e interoperabildades que ampliam exponencialmente as interações com a sociedade, permitindo oferta de serviços e produtos em interfaces de ambientes digitais como Facebook, YouTube e Twitter, entre outros. Na nova perspectiva, os museus buscam provocar a interação e reflexão do internauta, estimular o pensamento crítico e conversações a partir e além de seu objeto (WAGENSBERG, 2005).

A crescente dialogia entre sujeitos e instituições museológicas é fruto de políticas publicas para os museus, pois, segundo Marcelo Mattos Araújo, atual presidente do Instituto 
Brasileiro de Museus (Ibram), órgão do Ministério da Cultura, na contemporaneidade, "o debate no campo museológico no Brasil e no exterior tem se intensificado extraordinariamente, acompanhando as incessantes transformações e a visibilidade crescente dos nossos museus”. (ARAÚJO, 2013, p. 7). Na defesa deste ponto de vista, Araújo apresenta a publicação Conceitos-chave de Museologia:

[...] o Estado de São Paulo é um significativo recorte desse diversificado panorama museológico brasileiro. Além dos dezoito museus pertencentes à Secretaria de Estado da Cultura - dentre eles a Pinacoteca do Estado de São Paulo, parceira desta iniciativa -, o estado abriga mais de quatrocentas instituições museológicas, públicas e privadas, distribuídas em quase duzentas cidades paulistas (ARAÚJO, 2013, p. 8).

Além de São Paulo, no que se refere ao conjunto de museus em todo território nacional, pode-se verificar, no portal do Ibram, em sua publicação Guia dos Museus Brasileiros (Ibram/MinC), dados de 3.118 museus, incluindo 23 museus virtuais, mapeados. O ano de criação, situação atual, endereço, horário de funcionamento, tipologia de acervo, acessibilidade, infraestrutura para recebimento de turistas estrangeiros e natureza administrativa são as informações que o Guia nos fornece sobre cada um dos museus abordados ${ }^{1}$.

A propósito de museus virtuais, em Conceitos-chave de Museologia (ARAÚJO, 2013, p. 66), o termo "museu virtual" nos é apresentado como um conceito polêmico, colocando em perspectiva definições de termos como virtual, real e atual (uma discussão que tem sido explorada durante a pesquisa). Independentemente destas discussões, nosso objeto de estudo, o Museu da Pessoa (MP), reconhece-se e apresenta-se em ambiência digital como um museu virtual. Nesta direção, de acordo com Diogo Cutinhola, gerenciador de conteúdos criados internamente por pesquisadores da equipe do museu ou inseridos por internautas que chegam ao portal do MP online e em fluxo constante, o MP é um museu virtual, ainda que possua uma sede física e um setor educativo, por este espaço ser apenas administrativo e não abrigar exposições.

Por outro lado, a historiadora Karen Worcman, idealizadora e diretora do MP, acredita que, conceitualmente, o MP seja híbrido, não apenas pela existência da sede física administrativa, mas por ela abrigar acervo tanto digital quanto de mídias analógicas, custodiadas entre as paredes da sede, em Pinheiros, na cidade de São Paulo. A ação educativa institucional presencial, ainda que nem sempre em local fixo, também seria uma característica de ambiência híbrida. Segundo Worcman, o MP sai do museu: é um museu que anda e pode

\footnotetext{
${ }^{1}$ Link para o Guia dos Museus Brasileiros. Disponível em: https://www.museus.gov.br/os-museus/museus-dobrasil/>. Acesso em: 12 ago. 2016.
} 
vir a ser uma cabine que, presencialmente, atue. Além disto, às quintas-feiras, vídeos com depoimentos para a coleção Conte sua História são gravados pela equipe, sistematicamente, na sede física.

Estas conceituações distintas, provenientes da formação de cada indivíduo que compõem a equipe multidisciplinar do MP, convivem e são aceitas naturalmente. Por ora, apresentamos como polêmica gerada por tais problematizações conceituais a visão de Rose Miranda, Coordenadora Geral de Sistemas de Informação Museal do Instituto Brasileiro de Museus, sobre o MP: [...] cabe ressaltar que expressiva porcentagem de seu acervo e, portanto, de sua comunicação com o público, ainda se realiza no ciberespaço. Dessa forma, o Museu da Pessoa constitui-se em instituição híbrida ou mista (GUIA..., 2011, p. 21).

Segundo este Guia, o virtual é entendido como bem cultural que se apresenta mediado pela tecnologia de interação cibernética (Internet) (GUIA..., 2011). Isto equivale a dizer que a memória, um patrimônio cultural da humanidade, e, neste contexto, o acervo e fato museal (RÚSSIO, 2010) do MP, tem sido buscada e acessada por meio das TIC. Confirmando o aspecto sócio- cultural de instituições museológicas na pós-modernidade, Ferreira Brandão, presidente Instituto Brasileiro de Museus até 2016, declara:

[...] no universo da cultura, o museu assume funções as mais diversas e envolventes. [...] Espaço fascinante onde se descobre e se aprende, nele se amplia o conhecimento e se aprofunda a consciência da identidade, da solidariedade e da partilha. [...] Por meio dos museus, a vida social recupera a dimensão humana que se esvai na pressa da hora. As cidades encontram o espelho que lhes revele a face apagada no turbilhão do cotidiano. E cada pessoa acolhida por um museu acaba por saber mais de si mesma (OS MUSEUS, 2015, s.p).

Embora esta visão do papel social de museus traduza um entendimento bastante romantizado de uma realidade em que estes são menos efetivos, apontamos para o argumento de Wagensberg (2005), a saber, que o museu seja, ao menos, um espaço de conversação, cujos conteúdos estejam estrategicamente mediados institucionalmente por uma conceituação, organização e articulação discursiva, papel do profissional da informação envolvido na prática museal (museológicas e museográficas); um desígnio que pode ser compreendido dentro da perspectiva dialógica do DI, previstos em Curadoria Digital, por meio de recursos como tagueamento, taxonomias e folksonomia, cauda longa, entre outros, aqui estudados no âmbito da Ciência da Informação, a depender do desenvolvimento tecnológico da plataforma em relação à Web Semântica. 
Destaca-se que três museus internacionais, a exemplo do Museu da Pessoa brasileiro, foram criados posteriormente: na Universidade do Minho, Portugal (1999), um na Universidade de Indianna, EUA (2000) e, finalmente, um terceiro no Centro de História de Montreal, Canadá (2003). Embora autônomos, eles interligam-se por uma mesma metodologia - a Tecnologia Social da Memória ${ }^{2}$, desenvolvida pelo museu brasileiro -, e por objetivos comuns.

Diverso do modelo nacional, curiosamente, as iniciativas de Portugal, dos EUA e do Canadá, surgiram dentro do universo acadêmico, em instituições de ensino locais, como no Departamento de Informática da Universidade do Minho, no Departamento de Telecomunicações da Universidade de Indianna e no Centre de Francophonie de las Amérique, em Montreal. Note-se ainda que, além de as iniciativas terem sido originadas fora de ambiências tradicionais de museus, e dentro da academia, elas estão abrigadas em áreas interdisciplinares e em intersecções com a Ciência da Informação. Além disso, ao se procurar as interfaces destas outras vertentes, observa-se que as interfaces das ditas instituições ainda não foram disponibilizadas para uma possível comparação entre curadoria e design.

Quanto à metodologia, por meio de estudo histórico observado de forma planejada em ambiência digital, percebe-se que MP já era considerado virtual antes mesmo do advento da Internet, e que questões técnicas e tecnológicas, como as que se interligam a conceitos relacionados a patrimônio cultural e mediação institucional, entre outras, foram as perspectivas sobre as quais o MP se ergueu, em 1991, na cidade de São Paulo. Neste sentido, de acordo com tais temas e visão política, ética e social da instituição, buscou-se uma revisão bibliográfica segundo os temas de interesse do MP para a compreensão acadêmica e epistemológica do objeto deste estudo, assim como de conceitos e teorias que possam suportá-lo.

$\mathrm{O}$ artigo parte de pesquisa descritiva a fim de sistematizar conhecimentos sobre recursos de DI na Curadoria Digital do Museu da Pessoa, por meio de estudo histórico da instituição (dimensões epistemológica e contextual); revisão bibliográfica e documental (dimensões ética, política e teórica); participação indireta em observação planejada em ambiente digital, periódicos acadêmicos, teses e dissertações (meta-pesquisa), entre outras fontes para a formação de um quadro de análise (dimensões técnica e morfológica). A metodologia da pesquisa configura-se, assim, pela proposta pluridimensional de Bufrem (2013) que parte da

\footnotetext{
${ }^{2}$ Link para Tecnologia Social da Memória. Disponível em:

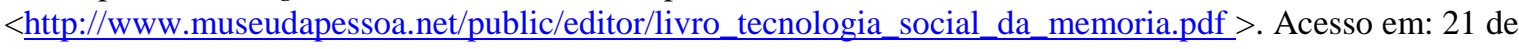
ago. 2016.
}

InCID: R. Ci. Inf. e Doc., Ribeirão Preto, v. 7, n. 2, p. 23-39, set. 2016/fev. 2017. 
Quadripolar, formulada por Bruyne, Herman e Schoutheete (1977), mas acrescida de dois importantes polos: o ético e o político.

\section{Fato Museal}

Memória, patrimônio cultural, inclusão social, bens culturais, espaços democráticos, físicos ou virtuais, e mediação institucional, foram os princípios sobre os quais o MP apoiouse para seu desenvolvimento. Vinte e seis anos depois, atualmente o MP possui sede administrativa na cidade de São Paulo e ambiência digital com alcance global, ubíquo e simultâneo. Epistemologicamente, memórias e história de vida pessoal foram determinadas como o seu fato museal ou objeto-conceito.

Segundo Rússio,

[...] o que caracteriza um museu é a intenção com que foi criado, e o reconhecimento público (o mais amplo possível) de que é efetivamente um museu, isto é, uma autêntica instituição. O museu é o local do fato "museal"; mas para que esse fato se verifique com toda a sua força, é necessário "musealizar" os objetos (os objetos materiais tanto quanto os objetos-conceito) (RÚSSIO, 2010, p. 125).

A percepção e o reconhecimento de histórias de vida como fato museal, aproximou-nos de iniciativas como o ambiente digital StoryCorps, nos EUA, e o ambiente digital do Museu da Pessoa $^{3}$, no Brasil, o foco deste artigo.

Em seu portal, nos links Histórico e Missão, o MP divulga sua crença na valorização da diversidade cultural e da história de cada pessoa como patrimônio da humanidade, o que contribui para a construção de uma cultura de paz. Sua principal missão é a de ser um museu aberto e colaborativo que transforme as histórias de vida de toda e qualquer pessoa em fonte de conhecimento, compreensão e conexão entre pessoas e povos. Segundo a página Missão e Objetivos do ambiente digital do $\mathrm{MP}^{4}$, trata-se de um legado diferenciado da história do país, que prioriza o desejo de transformação cultural e social, o que implica em construir uma massa crítica suficientemente grande para garantir a sustentabilidade da ideia e de sua ampliação em inúmeros segmentos e espaços sociais.

\footnotetext{
${ }^{3}$ Link para o Guia dos Museus Brasileiros. Disponível em: <https://www.museus.gov.br/os-museus/museus-dobrasil/>. Acesso em: 12 ago. 2015

${ }^{4}$ Link para Missão e Objetivos. Disponível em: < http://www.museudapessoa.net/pt/entenda/o-museu-dapessoa> Acesso em: 15 set. 2016.
}

InCID: R. Ci. Inf. e Doc., Ribeirão Preto, v. 7, n. 2, p. 23-39, set. 2016/fev. 2017. 
Essa é, declaradamente, uma forma conversacional de encarar o papel dos museus, pois, na história destas instituições, de gabinetes particulares de curiosidades (séc. VX e XVI) pertencentes à nobreza e à realeza, e que se abriam a público restrito, passando pelos museus modernos (séc. XVIII e XIX) e chegando ao museu contemporâneo, a conversação e a colaboração nem sempre foram vocação. Segundo Ribeiro (2010), no paradigma custodial, historicista, patrimonialista e tecnicista, a ideia da preservação e da guarda da memória teve sempre uma preferência muito grande em detrimento à ideia do acesso. Neste sentido,

[...] este papel de mediação deu, durante muito tempo, ao profissional da informação um estatuto de técnico especializado e erudito que o transformava num elemento indispensável no acesso à informação. Mas, por outro lado, a este papel de crucial importância acabava por, perversamente, se aliar um poder muito peculiar, um domínio sobre a informação que lhe permitia, discricionariamente, fornecer ou negar o acesso, facilitar ou dificultar a vida dos utilizadores, desvendar ou ocultar informação crítica, enfim, disponibilizar em nome do direito à informação ou guardar a sete chaves em nome da privacidade dos cidadãos ou dos interesses do Estado. (RIBEIRO, 2010, p. 64).

A pós-moderna explosão informacional oferece um novo desafio aos ambientes museais, tanto os físicos quanto os digitais. De acordo com as preconizações do paradigma conceito pós-custodial ou de custódia ampliada, este desafio só pode ser enfrentado por meio de uma visão da complexidade na qual os sistemas necessitam da disciplinaridade, das metodologias e das estratégias do DI para organizar e criar espaços de convergências de linguagens multimodais nos ambientes de disponibilização digital: bases de produção, armazenamento, recuperação e disseminação de conteúdos informacionais. Neste complexo universo cibernético, a soma das partes produz emergências que podem ser previstas por equipe de profissionais da informação em ambientes digitais de bibliotecas, arquivos e museus.

Sobre tais ambiências que ressignificam a CI e suas subáreas, em que convivem multidisciplinarmente e convergem em relações interdisciplinares (BICALHO; OLIVEIRA, 2011) na Web 2.0, questionamos, neste artigo, a própria disciplinaridade do DI. Diante deste contexto, algumas características da ambiência do MP chamam a atenção e delineiam o problema da pesquisa: como se desenham e se apresentam, atualmente, as informações no ambiente digital do MP, um projeto de Curadoria Digital de sistemas de memórias, na Web 2.0 ou Web Social Colaborativa. Como a atual plataforma customizável Shiro 1.0 do MP relacionase, cronologicamente, com as transformações das TIC desde o seu início, Web1.0, até a atualidade, em ambiência Web 2.0. A descrição que empreendemos neste artigo tratará, justamente, do papel do DI na Curadoria Digital do MP no ciberespaço. 


\title{
O museu da pessoa como ambiente designado para curadoria digital de memórias
}

Como, originalmente, o termo design provém da raiz romana designare, aproveitamos aqui a polissemia para pensar o design não apenas como desenho e recurso projetual, mas também como um ato designador, ou seja, como aquilo que determina, em nosso contexto, a apresentação da informação museal em interfaces de interação.

Em retrospectiva, o marco histórico da iniciativa do MP situa-se em dezembro de 1991. Segundo informações acessadas no portal, desde o seu princípio ele possuía características de um museu do século XXI, pretendendo-se um museu virtual antes mesmo da existência da Internet no Brasil. Em 1997, percebeu-se que a Internet, utilizada desde o ano anterior, poderia significar uma mudança dos paradigmas de acesso e participação, possibilitando, ao internauta, o registro de sua própria história.

\begin{abstract}
A idéia de criação de um museu virtual com as histórias das pessoas nasceu da necessidade de um espaço para o registro das histórias das pessoas. Não um espaço para armazenar as histórias das pessoas famosas, mas as histórias das pessoas anônimas que não são contempladas pela historiografia tradicional ou pelas mídias tradicionais. Nesse sentido, a criação de um museu com as histórias dos anônimos, baseada na premissa da democratização da informação, tornou-se possível não somente devido ao alargamento da noção de história e de patrimônio, mas também devido à própria redefinição do papel dos museus na sociedade (HENRIQUES, 2004, p. 77).
\end{abstract}

Do estudo histórico em observação planejada no ambiente digital do MP apreende-se que o seu acervo histórico, cultural e imaterial de histórias de vida foi, sucessivamente, sendo registrado em diferentes mídias, de analógicas a digitais. Desde 1997, quando teve início a primeira versão da seção Conte sua História, lançou-se um convite à criação de novos conteúdos a serem inseridos por profissional da informação no ambiente digital institucional nos moldes da Web 1.0: um e-mail era enviado pelo internauta e, num segundo momento, este conteúdo, após verificação, era inserido no ambiente pelo profissional do museu. Naquela fase de seu desenvolvimento, datas comemorativas, usualmente lembradas em ações culturais promovidas em museus tradicionais, tais como Dia das Mães, Dia dos Pais e Dia da Consciência Negra serviam como estímulo à colaboração e eram estratégias motivadoras de mediação, transferidas e imitadas no ambiente digital do MP. Então, uma única narrativa ficava online durante uma semana, devido a limitações Web 1.0. Tal prática é conceituada como top-down, ou seja, o conteúdo a ser divulgado é totalmente previsto e controlado pela instituição. Histórias de vida de qualquer pessoa, desde o princípio, eram tratadas como objeto da informação ou fato 
museal; porém, naquela fase o controle institucional sobre a informação era maior, e o sistema memorial, fechado.

\section{Curadoria digital na Web 1.0}

Como se observa de forma planejada no ambiente digital do MP, muito antes de contar com a Internet, ele já se reconhecia, no início dos anos noventa, como uma rede sem rede, tendo, como marco inicial, uma intervenção durante a exposição Memória \& Migração, evento realizado no Museu da Imagem e do Som (MIS), em São Paulo, em 1991. Na ocasião, abriu-se um estúdio para que toda pessoa interessada viesse contar e gravar sua história.

Em 1994, de uma parceria com o SESC-SP, surgiram os primeiros CDROMs históricos e interativos do Brasil, que resultou em seis exposições e uma grande coleção virtual. Na época, o objetivo do projeto era contar, por meio de histórias pessoais, a história do comércio em São Paulo. Ainda neste momento, desenvolveu-se a parceria entre o MP e a Central única dos Trabalhadores (CUT), para registro de histórias de profissões em extinção.

Em meados da década de 1990, o MP desenvolveu suas primeiras cabines móveis de captação de depoimentos em vídeo, o que deu origem ao projeto Museu que Anda. Então, as cabines de captação de vídeo circulavam por espaços públicos, como estações de Metrô e praças; e privados, como empresas e Shoppings, entre outros. Tratava-se de um estúdio itinerante para gravação de histórias sobre um mesmo tema e, como resultado do projeto, mais de 200 cabines circularam por todo o Brasil. A preocupação em socializar o conteúdo dos vídeos fez com que o MP buscasse outras mídias para criação de produtos de disseminação, tais como CD ROM's, livros e exposições. Entretanto, o que definitivamente provocou uma mudança de paradigma, e que veio a transformar práticas do MP, foi a chegada e a popularização da Internet no Brasil.

Em 1996, quando o MP construiu seu primeiro ambiente digital - Web 1.0-, reproduziuse a lógica do fluxo de informação característico dos jornais e livros, ou seja, do modelo (DI) do impresso, uma vez que o esforço inicial foi o de colocar as memórias na primeira interface digital que se caracterizava por uma única página e continha uma única história de vida, substituída semanalmente. Na ambiência Web 1.0, o MP, portanto, já lança mão de recursos do DI para a sua limitada curadoria digital de sistemas memoriais. Como mencionado, numa primeira versão do projeto Conte sua História, memórias pessoais eram enviadas por e-mail, 
pelos internautas, e colocadas no ar, via programação HTML, por profissional da informação do museu.

Do ponto de vista sócio- cultural, conforme se observa em estudo histórico sobre o MP, no próprio portal, apesar do país não possuir uma tradição em cultura escrita e de que, nos anos noventa, menos de $20 \%$ da população brasileira tinha acesso à Internet, internautas começaram a postar suas memórias e histórias, dando início ao projeto de construção de uma memória social, coletiva e democraticamente.

Posteriormente, a partir de 2001, em parceria com o Instituto Avisa Lá, o programa Memória Local passou a formar professores de escolas públicas do ensino fundamental, por meio da aplicação de material pedagógico desenvolvido por equipe multidisciplinar de profissionais do MP, a Tecnologia Social da Memória. Até 2016, cerca de 1300 organizações e escolas utilizaram-se deste material. Entre outros objetivos, a publicação destina-se a promover e suportar discussões sobre o que é um roteiro ou uma história de vida; sobre coleta de depoimentos e sobre a realização de entrevistas, resultando em conteúdo informacional de uma nova coleção virtual de memórias do MP.

Observa-se que a mesma metodologia foi utilizada para contar a história do São Paulo Futebol Clube, assim como para contar a história do comércio no Estado de São Paulo. Com o auxílio de uma linha do tempo simplificada, grandes marcos da trajetória da empresa foram identificados e, em um mapeamento, uma seleção de nomes de profissionais que representassem momentos históricos da empresa, cargos e funções, foram entrevistados. Das pesquisas e das histórias de vida, criaram-se produtos como centros de memória físicos e virtuais, livros, exposições e vídeos, entre outros. 


\section{Curadoria digital na Web 2.0}

Por volta de 2004, o MP repensou o seu papel como museu e passou a se preocupar em articular iniciativas a fim de que as histórias de vida se interconectassem e servissem como mobilizadoras de ações de diversos grupos sociais. Neste sentido, a iniciativa Brasil Memória em Rede, que envolveu cerca de 100 organizações em todo país, articulou ações em torno da memória. Em 2007, o MP havia se tornado uma espécie de centro de memória, o que possibilitou a construção de polos regionais, responsáveis pela articulação de projetos de memória em seus territórios. Naquele momento, pôde-se verificar dois movimentos no MP: um interno, nacional, e um no exterior, em busca de internacionalização. No Brasil, o movimento Um Milhão de História de Vida de Jovens; e, no exterior, as campanhas do Dia Internacional de Histórias de Vida, promovidas, entre outros, pela Rede Internacional de Museus das Pessoas.

O movimento Um milhão de Histórias de Vida de Jovens, acima mencionado, nasceu de uma parceria entre o MP e uma organização da sociedade civil, a Aracati; e ocupou-se da mobilização de jovens, utilizando-se de uma metodologia desenvolvida por Lambert (2002), fundador do movimento internacional Digital Storytelling e diretor executivo do Center for Digital Storytelling 5 , com o apoio da Fundação Kellog. Tratava-se de uma questão contemporânea: estimular os próprios jovens destas organizações a tornarem-se continuadores e facilitadores de círculos de narrativas de histórias (oral e posteriormente escrita em forma de roteiro para realização de vídeos curtos) para desenvolvimento de memórias a serem compartilhadas em ambiência digital. $\mathrm{O}$ desafio de inclusão digital era muito grande, pois os jovens estavam acostumados a narrar histórias no rádio, ou em versos, hip-hop ou em cordel, mas transformá-las, a fim de inseri-las em uma plataforma digital, seria uma nova experiência, diferente de, por exemplo, expô-las em um varal de histórias ou em uma peça teatral.

Quanto ao movimento em direção a uma internacionalização, neste mesmo período, a Rede Internacional de Museus das Pessoas chegava a seu melhor momento. Com início em 1999, em Portugal, e depois nos EUA, em 2001, e finalmente em Montreal, em 2003, os Museus das Pessoas, a partir de um contato com o MP nacional, e de capacitação de suas equipes, tornaram-se autônomos. Porém, foi em 2007, durante um encontro em Montreal, que se determinou e constituiu um Dia Internacional de Histórias de Vida, que a Rede se consolidou.

\footnotetext{
${ }^{5}$ Link para Center for digital storytelling. Disponível em: 〈http://www.storycenter.org>. Acesso em: 22 ago. 2016.
} 
O esforço passou a ser, a partir de então, o de constituir, não apenas uma rede de histórias, mas uma rede de organizações. Parte deste processo implicou em sistematizar e padronizar, de forma muito simples, a metodologia que o MP já utilizava, a partir da constatação de que muitas organizações registravam suas histórias, mas sem os meios adequados para processá-las e transformá-las em um acervo público e acessível. Dessa necessidade nasceu a já mencionada Tecnologia Social da Memória, uma metodologia que verte conceitos e ideias em práticas, como apoio a grupos sociais variados que dela pretendam se apropriar.

Em sua dissertação Memória, museologia e virtualidade: um estudo sobre o Museu da Pessoa, Henriques (2004) lembra-nos de que a Internet permite a convergência entre um eu publicável e o mundo por ser acessível a todos, não apenas para consulta, mas também para interações em ambiência digital. Porém, observa-se no portal da MP que até esta fase de desenvolvimento, as transformações tecnológicas não causam mudanças significativas quanto à interação e colaboração bottom-up do internauta. Quando as organizações em rede percebem que podem convergir e interoperar, oferecendo acesso e modos de interação e colaboração, novas tecnologias já haviam se desenvolvido, como se observa em estudo histórico. Tal evolução tecnológica reflete o uso de recursos de DI em Curadoria Digital, como tagueamento bottom-up (de baixo para cima) e top-down (de cima para baixo), e o uso de cauda longa, por exemplo, como recurso de busca, favorecendo o aumento de acessibilidade, a fim de propiciar uma percepção de interação e de fazer junto, de forma colaborativa.

Em 2008, o MP quase fechou suas portas devido à crise econômica que o país enfrentava. Naquele momento, o museu reviu suas estratégias e, impossibilitado em investir em internalização, voltou-se ao rico acervo que já havia construído. Como grande parte do acervo não havia sido digitalizada, e existia a necessidade de transcodificar o material até então registrado em mídias como hi 8 , betacam, mini dv, VHS (tecnologias de vídeo utilizadas ao longo dos anos, que foram convergidas para o ambiente digital e acessíveis por meio de linguagens digitais envolvidas nos processos de intersemioses e transcodificações), o contexto, apesar da crise econômica, ofereceu oportunidade para a realização de ações internas fundamentais para o MP, como a digitalização e transcodificação do acervo.

No tratamento de seu conteúdo informacional, o MP passou a priorizar a catalogação, a organização e a disseminação em ambiência Web 2.0. A curadoria digital da informação veio potencializar o acesso, a distribuição e a interatividade, resultantes de convergências previstas pelo DI até então subutilizado, limitado aos recursos da ambiência Web 1.0. Na mudança de 
ambiência de Web 1.0 para Web 2.0, a curadoria das histórias de vida, sua divulgação e a criação de meios de busca, - visando ampliar a função social do museu -, passou a ser a prioridade do MP.

Por exemplo, na seção acima mencionada, Conte sua História, na passagem para Web 2.0, graças a uma prévia Curadoria Digital, oportunizou-se, ao profissional mediador do conteúdo informacional institucional, e ao internauta, maior protagonismo ao lhes permitir, por um lado, administração mais eficiente de conteúdos e, ao internauta, a inserção de memórias pessoais de modo interativo, acompanhadas ou não de vídeos e imagens. A partir de então, esta seção passou a atrair atores da informação, profissionais ou não, nativos digitais ou não: um convite à participação e a criação de novos acervos para um museu em que se pode ser, ao mesmo tempo, o visitante, o fato museal e o curador de coleções de histórias de vida.

Em 2013, com o apoio institucional dos Correios, realizou-se uma grande expedição pelo país procurando histórias de conexão de pessoas antes da chegada da Internet. O projeto Aproximando Pessoas envolveu uma campanha virtual de histórias, o registro de oitenta e quatro histórias de vida, uma exposição e uma publicação. Ao mesmo tempo, a equipe de profissionais do MP, juntamente com o escritório de design Plano $\mathrm{B}^{6}$, desenvolvem uma plataforma costumizável para suas necessidades: um Content Management System (CMS) Shiro 1.0 com design 2013. Esta seria uma primeira experiência de mudança significativa, segundo administradores do portal do MP; e, a partir do aperfeiçoamento e de upgrades em relação ao primeiro Shiro 1.0, desenvolve-se um novo desenho de plataforma para qual pretende-se migrar.

\footnotetext{
${ }^{6}$ Link para o Plano B. Disponível em: 〈http://www.plano-b.com.br/>. Acesso em: 21 ago. 2016.
} InCID: R. Ci. Inf. e Doc., Ribeirão Preto, v. 7, n. 2, p. 23-39, set. 2016/fev. 2017. 


\section{Considerações}

O MP optou por um modelo de Curadoria Digital de sistema memorial que traz, em seu centro, histórias de vidas. Entidades relacionadas a esta história, como pessoa (autor da história), imagem, vídeos, coleções ou projeto ao qual pode pertencer determinada história, giram em torno dela e não em torno de uma pessoa ou seu autor, que pode, em tese, ter mais de uma história publicada no MP. Assim, uma história pode, ou não, conter vídeo ou imagem a ela atrelada, pertencer ou não a um projeto ou coleção, mas será acessada por meio de busca e busca avançada, devido ao uso de recurso de tags.

A plataforma idealizada pelo MP exigiu do Plano B e de sua equipe, composta por Sergio Boiteux (mestre em Design e Tecnologia), Pedro Herzog, (mestre em Design e Tecnologia), Durval Amorin (designer de interfaces), e Rafael Borges (desenvolvedor Web $e$ Sistemas de Informação) o desenvolvimento de um sistema a ser costumizável, como descreve Herzog (2014) em sua dissertação de mestrado: Sistema para indexação e visualização de depoimentos de história oral - O caso do Museu da Pessoa. Partindo de palavras-chave tais como História Oral, indexação, visualização de dados e folksonomia, Herzog envolve-se de forma particular com o MP, um museu epistemologicamente estruturado por historiadores e jornalistas e que se alimenta de História Oral. Em sua dissertação, o autor sugere recursos de design a serem adotados para indexação de trechos de vídeos, utilizando-se da plataforma Shiro 1.0, ainda em fase beta, desenvolvido em framework Code Igniter 17 (PHP/MySQL). O estudo e a análise sobre esta nova fase são parte de nosso trabalho investigativo, em andamento.

A plataforma, parafraseando Herzog (2014), é flexível no que diz respeito ao cadastro, relacionamento e anotação (tagueamento) de entidades. Uma plataforma com consistência menos dura, mais adaptável, e que se molda às necessidades de cada projeto. Segundo o autor, o pesquisador do museu poderá utilizar o ambiente administrativo de tal plataforma para indexar os trechos de vídeo a partir de princípios de tagueamento por trechos; e também da construção de relacionamentos entre esses trechos, voltados para a melhoria da recuperação da informação neles contida. Ainda segundo o autor, para designar esse tipo de tecnologia adaptável e customizavel, parte-se do princípio de que acervos de História Oral, como o MP, reúnem muitas horas de depoimentos em áudio e vídeos nos quais diversos assuntos são abordados, porém dificilmente encontrados sem assistirmos todo o vídeo ou ouvirmos todo o áudio (fontes primárias). Quando transcrito, o texto pode auxiliar em buscas pontuais de trechos das entrevistas, mas isto acaba por nos distanciar da fonte primária, o vídeo ou o áudio. A 
proposta de Herzog (2014) pretende ampliar o uso das fontes primárias e facilitar a encontrabilidade de trechos específicos de interesse do visitante do MP, indexando segmentos de vídeo e criando pontos de acesso imediato a entrevistas.

Dentre recursos da Ciência da Informação para classificação, o designer da informação propõe um tagueamento facilitador de busca e encontrabilidade de trechos (por termos) dos cerca de 1500 vídeos-depoimentos em canal do MP no YouTube; dois tipos de classificação que, segundo o autor, podem se transformar uma na outra: estrutura hierárquica (top-bottom) e classificação facetada (bottom-up). Acrescenta-se que ambas as abordagens são utilizadas no sistema de indexação proposto por Herzog:

A diferença conceitual, entretanto, é que a abordagem hierárquica resulta em uma ordem específica de classes e entidades, onde propriedades gerais estão localizadas no topo da hierarquia e as propriedades mais específicas ficam na base. Estruturas facetadas são mais flexíveis, permitindo a associação de entidades através de uma rede de relacionamentos. (HERZOG, 2014, p. 29).

Em linhas gerais, criou-se uma abordagem cruzada, tipo top-bottom, que organiza classes e subclasses, dos grandes grupos aos mais específicos. A abordagem bottom-up, diferentemente, baseia-se em um processo de análise e síntese, do nível fundamental das entidades (objetos indexados) até suas propriedades.

Os indexadores (termos, tags ou anotações), no modelo ainda a ser adotado no MP, não são associados ao vídeo completo, mas a pontos de entrada e saída (timecodes) que definem trechos específicos no vídeo. Neste modelo, a Curadoria Digital agrega conceitos e técnicas de áreas "aparentemente desconectadas: metodologias de indexação, construção de taxonomias, folksonomias, visualização de dados e Design de Interação são integrados em um processo unificado que vai desde a coleta e indexação dos depoimentos até sua visualização e interação" (HERZOG, 2014).

Tal desconexão é, entretanto, somente aparente. Existe, de fato, uma conexão entre níveis diferentes de sistemas. A impressão se justifica por nossa perspectiva de olhar estar contaminada por hábitos cartesianos de linearidade. Pensadas pelo viés da complexidade, entretanto, é justamente de tais partes aparentemente desconectadas que surgirão inúmeras e, por vezes, surpreendentes emergências, possibilidades e propriedades, ou affordances do sistema. No DI, consideramos, pois, que o princípio da complexidade dos sistemas é o regente de uma orquestração, ainda por ser explorada e consolidada como método na Ciência da Informação para o salto quântico necessário às formas de comunicação surgidas da aceitação da necessidade de conversação com os novos atores da informação: sujeitos protagonistas do 
século XXI que exigem dos profissionais da informação, entre eles o cientista da informação, novas competências para reais transformações paradigmáticas.

\section{Referencias}

ARAÚJO, M. M. Apresentação. In: DESVALLÉES, A.; MAIRESSE, F. (Ed.). Conceitoschave de Museologia. São Paulo: Comitê Brasileiro do Conselho Internacional de Museus: Pinacoteca do Estado de São Paulo: Secretaria de Estado da Cultura, 2013. Disponível em: $<$ http://icom.museum/fileadmin/user_upload/pdf/Key_Concepts_of_Museology/ConceitosChavedeMuseologia_pt.pdf $>$ Acesso em: 21 ago. 2016.

BICALHO, L. M.; OLIVEIRA, M. Aspectos contextuais da multidisciplinaridade e da interdisciplinaridade e a pesquisa em ciência da informação. Encontros Bibli: Revista Eletronica da Biblioteconomia e Ciencia da Informação, Florianópolis, v. 16, n. 32, p. 126, 2011. Disponível em: <https://periodicos.ufsc.br/index.php/eb/article/viewFile/15182924.2011v16n32p1/19336>. Acesso em: 21 ago. 2016.

BRUYNE, P.; HERMAN, J.; SHOUTHEETE, M. Dinâmica da pesquisa em ciências sociais: os pólos da prática metodológica. Rio de Janeiro: Francisco Alves, 1977.

BUFREM, L. S. Configurações da pesquisa em ciência da informação. DataGramaZero, v. 14, n. 6, 2013.

GUIA dos museus brasileiros. Brasília: Instituto Brasileiro de Museus, 2011. 592 p.

Disponível em: 〈http://www.museus.gov.br/wp-content/uploads/2011/05/gmb_extintos.pdf $>$. Acesso em: 21 ago. 2016.

HENRIQUES, R. Memória, museologia e virtualidade: um estudo sobre o Museu da Pessoa. 2004. 182 f. Dissertação (Mestrado em Museologia) - Departamento de Arquitectura, Urbanismo e Geografia, Universidade Lusófona de Humanidades e Tecnologias, Lisboa, 2004. Disponível em: <https://pesquisafacomufjf.files.wordpress.com/2013/06/memc3b3riamuseologia-e-virtualidade-um-estudo-sobre-o-museu-da-pessoa.pdf $>$. Acesso em: 21 ago. 2016.

HERZOG, P. Sistema para indexação e visualização de depoimentos de história oral - o caso do Museu da Pessoa. 2014. 90f. Dissertação (Mestrado em Design) - Escola Superior de Desenho Industrial, Universidade do Estado do Rio de Janeiro, Rio de Janeiro, 2014.

LAMBERT, J. Digital storytelling: capturing lives, creating community, Berkeley: Digital Diner Press, 2002.

OS MUSEUS. Portal do Instituto Brasileiro de Museus, Brasília, 2015. Disponível em: <http://www.museus.gov.br/os-museus/>. Acesso em: 28 ago. 2016.

RIBEIRO, F. Da mediação passiva à mediação pós-custodial: o papel da ciência da informação na sociedade em rede. Informação \& Sociedade, João Pessoa, v. 20, n. 1, p. 6370, jan./abr. 2010. Disponível em: <https://repositorioaberto.up.pt/bitstream/10216/80268/2/67122.pdf>. Acesso em: 21 ago. 2016. 
RÚSSIO, W. A interdisciplinaridade em museologia (1981). In: BRUNO, M. O. (Org.).

Waldisa Rússio Camargo Guarnieri: textos e contextos de uma trajetória profissional. São Paulo: Pinacoteca do Estado: Secretaria de Estado da Cultura: Comitê Brasileiro do Conselho Internacional de Museus, 2010. v. 1. p. 123-126.

SÁEZ VACAS, F. Vida y sociedade en el nuevo entorno tecnosocial. In: FUMERO, A.; ROCA, G., Redes Web 2.0. Fundación Orange, 2007. p. 96-122. Disponível em: <http://www.fundacionorange.es/areas/25_publicaciones/WEB_DEF_COMPLETO.pdf $>$. Acesso em: 21 ago. 2016.

SOARES BRULON, B.; CURY, M. X.; DESVALlÉES, A.; MAIRESSE, F.; Conceitoschave de Museologia. São Paulo: Comitê Brasileiro do Conselho Internacional de Museus: Pinacoteca do Estado de São Paulo: Secretaria de Estado da Cultura, 2013. Disponível em: $<$ http://icom.museum/fileadmin/user_upload/pdf/Key_Concepts_of_Museology/ConceitosChavedeMuseologia_pt.pdf $>$.Acesso em 15 set. 2016.

WAGENSBERG, J. O museu 'total', uma ferramenta para a mudança social. In: CONGRESSO MUNDIAL DE CENTROS DE CIÊNCIA, 4., 2005, Rio de Janeiro. Anais... Rio de Janeiro: Fiocruz, 2005. Disponível em: <http://www.museudavida.fiocruz.br/4scwc/Texto\%20Provocativo\%20\%20Jorge\%20Wagensberg.pdf>. Acesso em: 28 ago. 2016. 